\title{
ESCAPEing from bad-quality air: a cleaner air, from Europe to elsewhere
}

\author{
Joan B. Soriano ${ }^{1}$, Pippa Powell ${ }^{2}$ and Steve Sealy ${ }^{3}$ \\ Affiliations: ${ }^{1}$ IdISPa-FISIB, Hospital Universitari Son Espases, Palma De Mallorca, Spain. ${ }^{2}$ European Lung
} Foundation, Sheffield, UK. ${ }^{3}$ European Respiratory Society, Lausanne, Switzerland.

Correspondence: Joan B. Soriano, IdISPa-FISIB, Hospital Universitari Son Espases, Unitat Assaigs Clínics Mòdul I, Nivel -1, Despatx 2, Carretera de Valldemossa, 7907010 Palma de Mallorca, Spain. E-mail: jbsoriano2agmail.com

0

@ERSpublications

The ESCAPE project contributes important evidence to the EU air quality policy debate http://ow.ly/CnD0m

There are many areas of life we don't fully understand: how do babies learn to speak? Why do we sometimes laugh while reading? Why did Peter Sellers never receive an Oscar? Making the connections is not always easy. In a similar way, seasoned respiratory experts often say there are two types of respiratory research that are intrinsically difficult: anything related to tobacco, and environmental epidemiology.

In medicine, it is often difficult to prove causal associations and establish mechanisms between exposures and health events that not only make sense but are plausible and coherent, the two most elusive of Sir Austin Bradford Hills' criteria [1]. In this issue of the European Respiratory Journal (ERJ), ADAM et al. [2] report an epidemiological study of air pollution and lung health. They aimed to investigate the association between long-term exposure to ambient air pollution and lung function in adults. They studied five of the 30 cohorts in the eight countries participating in the European Study of Cohorts for Air Pollution Effects (ESCAPE), which measured and modelled the outdoor levels of air pollution at participants' home addresses in a standardised manner. ADAM et al. [2] assessed the outcomes of spirometry tests (performed 10 years apart) in participants. Their findings contribute important evidence towards the air quality policy debate in the European Union (EU). In the largest Europe-wide meta-analysis of its kind to date, they have identified associations between lung function and nitrogen oxides $\left(\mathrm{NO}_{2}\right.$ and $\left.\mathrm{NO}_{\mathrm{x}}\right)$ and particulate matter with a $50 \%$ cut-off aerodynamic diameter of $10 \mu \mathrm{m}$ (PM10).

The ESCAPE project is a unique, ambitious and unprecedented collaborative network with a growing list of deliverables [3]. It links spirometric parameters, such as forced expiratory volume in $1 \mathrm{~s}(\mathrm{FEV} 1)$ and forced vital capacity (FVC), in 7613 subjects, whose results were combined and analysed using both standard and sophisticated meta-analysis techniques. Although the study is not conclusive per se (and could even be considered to be negative with regard to its primary objective, as they did not observe an association between air pollution and the longitudinal change in lung function), they did observe that a $10-\mu \mathrm{g} \cdot \mathrm{m}^{-3}$ increase in $\mathrm{NO}_{2}$ and $\mathrm{PM} 10$ exposure was associated with lower levels of FEV1and FVC, and this association was particularly strong in obese people. Again, studying lung function decline, even in labs with experienced technicians and excellent quality control, has insurmountable complications [4].

There is incontrovertible evidence that outdoor pollution contributes to total and respiratory-specific morbidity and mortality, some which has been recently confirmed by ESCAPE [5]. Less clear is the link between ambient air pollution and chronic obstructive pulmonary disease (COPD), both in terms of

Received: Sept 152014 | Accepted: Sept 162014

Conflict of interest: P. Powell is an employee of the European Lung Foundation. S. Sealy is an employee of the European Respiratory Society.

Copyright OERS 2015 
incidence as well as lung function. But in a way, the same statement could be applied to second-hand smoke (SHS). While tobacco smoking has been causally associated with COPD since the 1964 Surgeon General's Report, the causative role of SHS exposure on COPD incidence and mortality remains unconfirmed. According to the 2006 Surgeon General Report update and a 2010 report from the American Thoracic Society, the available evidence is limited and suggestive of but not sufficient to infer a causal relationship between SHS exposure and COPD risk [6]. SHS exposure and COPD is a model for environmental pollution and COPD. Imagine if someone breathes in air from the exhaust of a car or a truck, for hours every day, and for many years...

Yet these hot issues are surrounded by obstacles, both in terms of measurement and practicality. Even in the über-controlled world of randomised trials of respiratory drugs, it is somehow more difficult to identify an association between a respiratory drug and changes in lung function decline, than it is with reductions in total and respiratory-specific mortality [7]. ADAM et al. [2] used, and even developed de novo, analytical tools to deal with measurement error to assess the most common outdoor pollutants, mainly traffic-related, such as $\mathrm{NO}_{2}$, NOx and PM metrics measured between 2008 and 2011, all based in monitoring units close to residential homes. Tools included land-use regression, multivariable mixed linear regression models with a random intercept, and other models, including plenty of back-extrapolation for missing values and variables; certainly not made for interpretation by the mere mortal or even the average clinician. There were also subgroup analyses by age, sex, obesity, smoking status, asthma-ever and geographic clustering of outcomes, and extra sensitivity analyses to avoid/reduce ecological fallacies, selection and information biases, as well as confounding. Most ESCAPE participants were younger adults (mean age 53 years), of whom a quarter were current-smokers and a third were already ex-smokers, with of course no children and few elderly participants included, as both of these groups would be likely to be more susceptible to the deleterious effect of outdoor exposures. It would add consistency to the conclusions if the associations were stronger not only in obese people but also in women, continuous- or ex-smokers, and asthmatics, although as the authors present in table 8 of the online supplementary material, neither $\mathrm{NO}_{2}$ nor any of the others showed modification of the air pollution-lung function association.

The authors have to be praised, yet no study is totally perfect, and this study has several drawbacks, beyond those identified in their limitations section. Compared to findings in respiratory drug trials, the noise to effect ratio of pre-bronchodilator spirometry measurements, with little to no quality control calculating slopes with a maximum of two spirometry measurements, makes it difficult to obtain a positive finding. An obesity threshold of a body mass index of (BMI) $\geq 30 \mathrm{~kg} \cdot \mathrm{m}^{-2}$ is actually becoming normal, if normal means frequent, in many European countries and elsewhere. However, the perfect natural history study of lung function in the population [4, 8], which would be required for full, definitive type A evidence of the need to reduce outdoor air pollution, is difficult, perhaps impossible, and we might never have it.

The cleaner outdoor air that we are experiencing in most of Europe is largely thanks to science from tireless environmental researchers who have convinced politicians to control exhausts from factories and vehicles, and reduce risky exposures to all, thereby increasing respiratory and total health, and more than likely already helping with life expectancy [9]. The ongoing European Respiratory Society/European Lung Foundation "Healthy Lungs for Life" (HLfL) global initiative aims to raise awareness about lung health amongst all stakeholders in respiratory medicine, from scientists and clinicians to the public and policy makers. In its inaugural year (September 2014 to September 2015), this wide-reaching campaign will focus on the theme "Breathe Clean Air". We must all spread the message of the importance of clean air for lung health, and HLfL provides us with the tools to do so. Go to www.healthylungsforlife.org for more information, statistics and resources, and find out how you can lend your support by holding a World Spirometry Day event or simply sharing the information provided. ESCAPEing from bad quality air with a general goal to achieving cleaner air appears to be a win-win situation in Europe and across the globe. We need more and better evidence on the harmful effects of pollution, and on the beneficial effects to the lungs and the bodies of all those who enjoy cleaner air.

\section{References}

1 Hill AB. The environment and disease: association or causation? Proc R Soc Med 1965; 58: 295-300.

2 Adam M, Schikowski T, Carsin AE, et al. Adult lung function and long-term air pollution exposure. ESCAPE: a multicentre cohort study and meta-analysis. Eur Respir J 2015; 45: 38-50.

3 ESCAPE - European Study of Cohorts for Air Pollution Effects. www.escapeproject.eu/publications.php Date last accessed: August 12, 2014. Date last updated: August 25, 2014.

4 Kohansal R, Soriano JB, Agusti A. Investigating the natural history of lung function. Chest 2009; 135: 1330-1341.

5 Beelen R, Raaschou-Nielsen O, Stafoggia M, et al. Effects of long-term exposure to air pollution on natural-cause mortality: an analysis of 22 European cohorts within the multicentre ESCAPE project. Lancet 2014; 383: 785-795. 
6 Eisner MD, Anthonisen N, Coultas D, et al. An official American Thoracic Society public policy statement: novel risk factors and the global burden of chronic obstructive pulmonary disease. Am J Respir Crit Care Med 2010; 182: 693-718.

7 Celli BR. The light at the end of the tunnel: is COPD prevalence changing? Eur Respir J 2010; 36: 718-719.

8 Miller A, Raskin JM. The natural history of COPD: confirming and going beyond Fletcher and Peto. Eur Respir J 2014; 44: 280-283.

9 Christensen K, Doblhammer G, Rau R, et al. Ageing populations: the challenges ahead. Lancet 2009; 374: 1196-208. 